Revista Brasileira de Agricultura Irrigada v.7, n. 2, p. 112 - 127, 2013

ISSN 1982-7679 (On-line)

Fortaleza, CE, INOVAGRI - http://www.inovagri.org.br

DOI: $10.7127 /$ rbai.v7n200009

Protocolo 009.13 - 28/02/2013 Aprovado em 25/04/2013

\title{
AVALIAÇÃO DE MODELOS DE ESTIMATIVA DE PRODUTIVIDADE DA CANA- DE-AÇÚCAR IRRIGADA EM JAÍBA-MG
}

\author{
Henrique Faria de Oliveira ${ }^{1}$, Everardo Chartuni Mantovani ${ }^{2}$, Gilberto Chohaku Sediyama ${ }^{3}$
}

\section{RESUMO}

Com o presente trabalho objetivou-se avaliar os modelos de estimativa de produtividade de Stewart, que relaciona a produtividade da cultura com a evapotranspiração, e o de Mantovani, que relaciona a produtividade da cultura com a água de irrigação e a uniformidade de aplicação. Os modelos foram avaliados utilizando a cultura cana-de-açúcar irrigada, cultivar RB 86-7515, safras de 2007/2008 e 2008/2009, no município de Jaíba, Minas Gerais. Para simular e avaliar os modelos foi desenvolvido um software. De acordo com os testes estatísticos, o modelo de Stewart apresentou ótimo desempenho nas duas safras, tendo em vista que os dados estimados não apresentaram diferenças significativas com os dados observados em campo. O modelo de Mantovani apresentou diferença significativa entre os dados estimados e observados em campo nas duas safras, o coeficiente de déficit calculado por ciclo total influenciou na superestimativa da produtividade da cana-de-açúcar.

Palavras-chave: Evapotranspiração, uniformidade de aplicação, coeficiente de déficit.

\section{EVALUATION OF MODELS TO ESTIMATE THE PRODUCTIVITY OF IRRIGATED SUGAR CANE AT JAÍBA-MG}

\begin{abstract}
The present study aimed to evaluate the yield models estimation of Stewart, which relates the yield with evapotranspiration, and Mantovani, which relates the yield on and irrigation water application uniformity. The models were evaluated using the irrigated sugarcane RB 86-7515 cultivar, crops of 2007/2008 and 2008/2009, at city of Jaíba, Minas Gerais. To simulate and evaluate the models a software was developed. According to the statistical tests, the Stewart's model showed excellent performance in both crops, considering that the estimated data showed no significant difference with the data observed in the field. The Mantovani's model showed significant difference with the data observed in the field in both crops, the coefficient of deficit calculated by the total cycle influenced the overestimation of yield of sugarcane.

Keywords: Evapotranspiration, application uniformity, coefficient of deficit.
\end{abstract}

\footnotetext{
${ }^{1}$ M.Sc. Meteorologia Agrícola, Professor, Departamento de Informática, IFNMG, Januária-MG, henrique.faria@ifnmg.edu.br.

2 D.Sc. Engenharia Agrícola, Professor, Departamento de Engenharia Agrícola, UFV, Viçosa-MG, everardo@ufv.br.

${ }^{3}$ Ph.D. Engenharia Agrícola, Professor, Departamento de Engenharia Agrícola, UFV, Viçosa-MG, g.sediyama@ufv.br.
} 
AVALIAÇÃO DE MODELOS DE ESTIMATIVA DE PRODUTIVIDADE DA CANAINTRODUÇÃO

DE-AÇÚCAR IRRIGADA EM JAÍBA-MG

Um dos importantes desafios da agricultura atual é melhorar a qualidade dos produtos, associado à preservação do meio ambiente, com benefícios sustentáveis nas explorações agrícolas. É de grande importância o desenvolvimento de estratégias de manejo fundamentado em princípios científicos para os destinos de uma agricultura racional (Mantovani; Bernardo; Palaretti, 2009). Devido à tendência de decréscimo da disponibilidade de água para a agricultura (LÓPEZ-MATA et al., 2010), é crescente a preocupação mundial com os recursos hídricos levando à adoção de estratégias de manejo que possibilitem economia de água sem prejuízos da produtividade das culturas.

Dentro deste panorama, destaca-se o termo função de produção, que se aplica genericamente a qualquer relação entre a resposta da cultura a um determinado fator. Uma ferramenta importante, neste estudo, são os modelos de simulação para predição do crescimento, desenvolvimento e produção das culturas (Mantovani et al., 2010).

O uso de modelos de produtividades assume grande importância em estudos com esse objetivo, caracterizando-se como importante ferramenta de assistência à tomada de decisão para viabilizar sistemas racionais de produção. Apesar da complexidade envolvida na construção desses modelos, os esforços são compensados em função de sua grande aplicabilidade.

Segundo Mantovani (2012), as funções de produção permitem estimar a produtividade de uma cultura em diferentes cenários, e vários deles relacionam a uniformidade de irrigação e a produtividade de determinada cultura. Dentre os modelos de simulação de produtividade disponíveis, destaca-se o Modelo de Stewart (Doorenbos \& Kassam, 1979), que relaciona a produtividade com a evapotranspiração da cultura, e o Modelo de Mantovani (Mantovani, 1993), que relaciona a produtividade da cultura com a água de irrigação e a uniformidade de aplicação.

No software Irriplus estão disponíveis as mais modernas técnicas aplicadas à agricultura, ferramentas poderosas para o planejamento da exploração racional e auto-sustentada da propriedade agrícola, permitindo um manejo integrado das culturas agrícolas. $\mathrm{O}$ sistema permite ao usuário a simulação de plantio com balanço hídrico detalhado durante todo o ciclo da cultura, criando vários níveis de decisões, além de possibilitar o levantamento de dados para projetos de irrigação e drenagem (Mantovani; Bernardo; Palaretti, 2009). Entretanto, o software não tem nenhuma ferramenta disponível para estimativa de produtividade.

Atualmente, com o agravamento do efeito estufa e aquecimento global, intensificaram-se as pesquisas em busca de fonte renováveis. Segundo Megda et al. (2012), a cana-de-açúcar é a cultura mais promissora entre as produtoras de biocombustíveis renováveis, e o etanol é considerado a alternativa mais viável para a substituição dos derivados do petróleo. De acordo com Silva et al. (2009), a produtividade da cana-de-açúcar é altamente dependente das interações entre suas fases fenológicas e as variações climáticas, sendo o rendimento agrícola afetado diretamente por estas condições.

Diante do exposto, e considerando-se a relevância da cana-de-açúcar, principalmente devido à produção de etanol, pretendeu-se, com essa pesquisa, incluir no software Irriplus os modelos de estimativa de produtividade de Stewart e Mantovani e avaliá-los com a cultura da cana-de-açúcar, para caracterizar as alternativas de manejo e aumentar a eficácia das decisões gerenciais e estratégicas ao longo da safra. 


\section{AVALIAÇÃO DE MODELOS DE ESTIMATIVA DE PRODUTIVIDADE DA CANA- DE-AÇÚCAR IRRIGADA EM JAÍBA-MG}

\section{MATERIAL E MÉTODOS}

Foram utilizados dados de produção da cana-de-açúcar cultivar RB 86-7515, safras de 2007/2008 e 2008/2009, do município de Jaíba localizado no Norte do estado de Minas Gerais. As coordenadas geográficas do município são: $15^{\circ} 20^{\prime} 16^{\prime \prime}$ de latitude Sul, 43\%40'26" de longitude Oeste e $478 \mathrm{~m}$ de altitude.

Os modelos foram simulados no software Irriplus, sendo todos os dados de cultura, solo, clima e irrigação, cedidos pela Fazenda SADA Bio-Energia, que possui uma área de 4.735 ha de plantação cultivada com cana-de-açúcar. No total, foram avaliadas 25 parcelas na safra de 2007/2008 e 27 na safra de 2008/2009. Cada parcela possui uma área média de 70 ha, sendo todas irrigadas por pivô-central.

O modelo de Stewart (Doorenbos \& Kassam, 1979), está descrito pela Equação 1.

$$
P=P_{\max }\left[1-K y\left(1-\frac{E T c}{E T m}\right)\right]
$$

em que, $\mathrm{P}$ é a produtividade real da cultura $\left(\mathrm{t} \mathrm{ha}{ }^{-1}\right) ; \mathrm{P}_{\max }$ é a produtividade máxima da cultura $\left(\mathrm{t} \mathrm{ha}{ }^{-1}\right) ; \mathrm{Ky}$ é $\mathrm{o}$ coeficiente empírico, que representa a sensibilidade da cultura ao déficit hídrico (adimensional); ETc é o total da evapotranspiração da cultura durante seu ciclo $(\mathrm{mm})$; ETm é o total da evapotranspiração máxima da cultura durante seu ciclo (mm).

Para estimar a $\mathrm{P}_{\max }$ foi utilizado o Método da Zona Agroecológica (MZA), proposto por Doorenbos \& Kassam (1979) descrito pela Equação 2. Este método pressupõe que a produtividade de uma cultura bem adaptada ao respectivo ambiente de crescimento, sem limitações hídricas e nutricionais, e sem ocorrência de doenças e pragas, seja condicionada apenas pela interação entre características genéticas da cultura e as condições climáticas.

$$
P_{\max }=c L c N c H G[F(a+b y m) y o n+(1-F)(c+d y m) y c]
$$

em que, $\mathrm{P}_{\max }$ é a produtividade máxima da cultura $\left(\mathrm{kg} \mathrm{ha}^{-1}\right)$; $\mathrm{cL}$ é a correção em função do desenvolvimento da cultura e área foliar (adimensional); $\mathrm{cN}$ é a correção para a produção de matéria seca (adimensional); $\mathrm{cH}$ é a correção para a parte colhida (adimensional); G é o período total de crescimento (dia); F é a fração do dia em que o sol fica encoberto por nuvens (adimensional); ym é a taxa de produção de matéria seca de folhas $\left(\mathrm{kg} \mathrm{ha}^{-1} \mathrm{~h}^{-1}\right)$; yon é a taxa de produção bruta de matéria seca da cultura-padrão em dia completamente nublado $\left(\mathrm{kg} \mathrm{ha}^{-1} \mathrm{~h}^{-1}\right)$; yc é a taxa de produção bruta de matéria seca de uma cultura-padrão em dia sem nuvens $\left(\mathrm{kg} \mathrm{ha}^{-1} \mathrm{~h}^{-1}\right)$. Segundo Doorenbos \& Kassam (1979), os valores de a, b, c e d são iguais a 0,8, 0,01, 0,5 e 0,025, respectivamente para a $\mathrm{ym} \geq 20 \mathrm{~kg} \mathrm{ha}^{-1} \mathrm{~h}^{-1}$ e iguais a $0,5,0,025,0,0$ e 0,05 , respectivamente, para a ym $<20 \mathrm{~kg} \mathrm{ha}^{-1} \mathrm{~h}^{-1}$.

Considerou-se a cL igual a 0,5, conforme sugerido por Doorenbos \& Kassam (1979), para a cultura da cana-deaçúcar. A cH é a razão entre a produção obtida e matéria seca total, nesta pesquisa foi considerado a produção total obtida da cana-de-açúcar, sendo o cH igual a 1,00.

Segundo Doorenbos \& Kassam (1979), A cN é igual a 0,60 quando a temperatura média (Tm) for inferior a 20
${ }^{\circ} \mathrm{C}$ e 0,50 quando a $\mathrm{Tm}$ for igual ou superior a $20^{\circ} \mathrm{C}$. A ym, conforme a Tabela 1, é estimada em função da Tm, e a $\mathrm{F}$ (Equação 3) é estimada em função da radiação efetiva de ondas curtas para dias claros (Rse) e radiação de ondas curtas (Rs).

O Ky foi estimado de acordo com os estádios de desenvolvimento da cultura da cana-de-açúcar estabelecidos na Tabela 2. 


\section{AVALIAÇÃO DE MODELOS DE ESTIMATIVA DE PRODUTIVIDADE DA CANA- DE-AÇÚCAR IRRIGADA EM JAÍBA-MG}

Tabela 1 - Valores de ym $\left(\mathrm{kg} \mathrm{ha}^{-1} \mathrm{~h}^{-1}\right)$ para a cultura da cana-de-açúcar em função da temperatura média durante o ciclo da cultura.

\begin{tabular}{cc}
\hline Tm $\left({ }^{\circ} \mathrm{C}\right)$ & ym \\
\hline Até 10 & 0 \\
Até 15 & 5 \\
Até 20 & 45 \\
Até 35 & 65 \\
Até 40 & 45 \\
Acima de 40 & 5 \\
\hline
\end{tabular}

Fonte: Doorenbos \& Kassam (1979).

$$
F=\frac{R s e-0,5 R s}{0,8 \text { Rse }}
$$

Tabela 2 - Valores médios do coeficiente de cultura $(\mathrm{Kc})$ e coeficiente empírico que representa a sensibilidade da cultura ao déficit hídrico (Ky), em função do estádios de desenvolvimento da cultura cana-de-açúcar e para o período total de crescimento.

\begin{tabular}{llll}
\hline Estádios & Definição & Ky & Kc \\
\hline Inicial & Estabelecimento & 0,75 & 0,45 \\
Crescimento & Período vegetativo & 0,75 & 0,85 \\
Produção & Floração até início da maturação & 0,50 & 1,15 \\
Maturação & Início da maturação até a colheita & 0,10 & 0,55 \\
\hline Ciclo & Período total de crescimento & 1,20 & 1,20
\end{tabular}

Fonte: Doorenbos \& Kassam (1979).

Para estimar a ETm (Equação 4), utilizou-se o conceito de coeficiente de cultura (Kc) e evapotranspiração de referencia (ETo), proposto por Doorenbos
\& Pruitt (1977). Segundo estes autores, o Kc é determinado empiricamente e varia para cada tipo de cultura e seu estádio de desenvolvimento.

\section{$\boldsymbol{E T m}=\boldsymbol{K C} \boldsymbol{E T o}$}

em que, ETm é a evapotranspiração máxima da cultura $\left(\mathrm{mm} \mathrm{d}^{-1}\right)$; Kc é o coeficiente de cultura (adimensional); ETo é a evapotranspiração de referência $\left(\mathrm{mm} \mathrm{d}^{-1}\right)$.

\begin{abstract}
Doorenbos \& Kassam (1979) reuniram grande quantidade de informações sobre Kc apresentando amplo estudo para a maioria das espécies cultivadas comercialmente. $\mathrm{O}$ método consiste em dividir o ciclo da cultura em fases de desenvolvimento definindo-se um
\end{abstract}

Kc específico para cada fase. Na Tabela 2 estão apresentados os valores de Kc para a cultura da cana-de-açúcar. Allen et al. (1998) atualizaram essa metodologia, para ajustar os $\mathrm{Kc}$ em razão de variações climáticas, conforme a Equação 5. 


\section{AVALIAÇÃO DE MODELOS DE ESTIMATIVA DE PRODUTIVIDADE DA CANA- DE-AÇÚCAR IRRIGADA EM JAÍBA-MG}

$$
K c=K c_{t a b}+\left[0,04\left(U_{2}-2\right)-0,004\left(U R_{\min }-45\right)\right]\left(\frac{h}{3}\right)^{0,3}
$$

em que, $\mathrm{Kc}_{\mathrm{tab}}$ é o Kc tabelado (adimensional); $\mathrm{U}_{2}$ é a velocidade média do vento a $2 \mathrm{~m}$ de altura $\left(\mathrm{m} \mathrm{s}^{-1}\right) ; \mathrm{UR}_{\min }$ é a média da umidade relativa mínima diária (\%); e h é a altura da planta (m).

O método utilizado para estimar a Monteith, (Pereira et al., 2010). ETo (Equação 6) foi o de Penman-

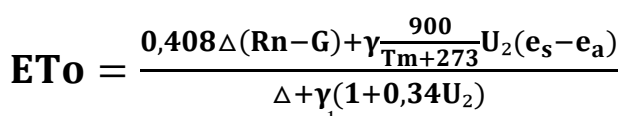

em que, ETo a é evapotranspiração de referência $\left(\mathrm{mm} \mathrm{d}^{-1}\right)$; Rn é o saldo de radiação à superfície da cultura (MJ $\left.\mathrm{m}^{-2} \mathrm{~d}^{-1}\right) ; \mathrm{G}$ é a densidade do fluxo de calor do solo $\left(\mathrm{MJ} \mathrm{m}^{-2} \mathrm{~d}^{-1}\right) ; \gamma$, coeficiente psicrométrico $\left(\mathrm{kPa}^{\circ} \mathrm{C}^{-1}\right) ; \mathrm{Tm}$ é a temperatura média diária $\left({ }^{\circ} \mathrm{C}\right) ; \mathrm{U}_{2}$ é a velocidade do vento a $2 \mathrm{~m}$ de altura $\left(\mathrm{m} \mathrm{s}^{-1}\right)$; $\mathrm{e}_{\mathrm{s}}$ é a pressão de saturação de vapor $(\mathrm{kPa}) ; \mathrm{e}_{\mathrm{a}}$ é a pressão atual do ar $(\mathrm{kPa}) ; \Delta$ é a declividade da curva de pressão de saturação de vapor (kPa $\left.{ }^{\circ} \mathrm{C}^{-1}\right)$

Para estimar a ETc (Equação 7), Bernardo; Palaretti, 2009), que é bastante utilizou-se o método FAO (Mantovani; utilizado na área de gestão de irrigação.

$$
E T c=E T o K c K s
$$

em que, ETc é a evapotranspiração da cultura $\left(\mathrm{mm} \mathrm{d}^{-1}\right)$; Ks é o coeficiente de estresse hídrico (adimensional).

$$
K S=\frac{\ln [L A A+1]}{\ln [C T A+1]}
$$

em que, LAA é a lâmina real de água no solo (mm); CTA é a capacidade total de água no solo (mm).

O modelo de Mantovani (Mantovani, de Stewart, descrito pela Equação 9. 1993), foi desenvolvido a partir do modelo

$$
P=P_{\max }[1-k y C d(1-p)]
$$

em que, Cd é o coeficiente de déficit (adimensional); $p$ é a fração da evapotranspiração máxima da cultura suprida por outras fontes de água diferentes da irrigação (adimensional).

A $\mathrm{P}_{\max }$ foi estimada pelo MZA (Equação 2), e o Ky foi estimado de acordo com os estádios de desenvolvimento da cultura da cana-de-açúcar apresentados na Tabela 2.

$\mathrm{O} \mathrm{Cd}$ é um índice relacionado ao manejo de água e ao atendimento da demanda hídrica da cultura pela irrigação, apresentando um componente tecnológico associado à eficiência do manejo e outro estratégico associado à magnitude da lâmina de irrigação a ser aplicada.

Para a estimativa do $\mathrm{Cd}$, Mantovani (1993) considerou que o perfil de distribuição de água pelos aspersores segue uma distribuição uniforme, função linear. Faccioli (2002) atualizou a metodologia propondo para o $\mathrm{Cd}$ uma distribuição normal, descrito pela Equação 10, ao qual foi utilizado nesta pesquisa. 
AVALIAÇÃO DE MODELOS DE ESTIMATIVA DE PRODUTIVIDADE DA CANADE-AÇÚCAR IRRIGADA EM JAÍBA-MG

$$
C d= \begin{cases}{\left[\frac{\left(\frac{4,548(1-C U C)-1+\frac{L_{r}}{L_{b}}}{1,407(1-C U C)}\right)^{3,322}}{100}\right]\left(1-\frac{L_{b}}{L_{r}}\right)+\frac{(1-C U C)}{2} \frac{L_{b}}{L_{r}}, L_{b} \geq L_{r}} \\ 1-\frac{L_{b}}{L_{r}}, & L_{b}<L_{r}\end{cases}
$$

em que, CUC é o coeficiente de uniformidade de Christiansen (decimal); $\mathrm{L}_{\mathrm{b}}$ é a lâmina bruta aplicada na cultura durante seu ciclo fenológico $(\mathrm{mm}) ; \mathrm{L}_{\mathrm{r}}$ é a lâmina requerida pela cultura durante seu ciclo fenológico $(\mathrm{mm})$.

Foi considerado a $\mathrm{L}_{\mathrm{r}}$ igual a ETc e a $\mathrm{L}_{\mathrm{b}}$ igual a irrigação aplicada durante $\mathrm{o}$ ciclo fenológico na cultura. Procedeu-se o cálculo do coeficiente de uniformidade por meio da Equação 11, conforme Christiansen (1942), modificado por Heermann \& Hein (1968).

$$
C U C=100\left[1-\frac{\sum_{i=1}^{n} s_{i}\left|X_{i}-\bar{X}\right|}{\bar{X} \sum_{i=1}^{n} s_{i}}\right]
$$

em que, CUC é o coeficiente de uniformidade de Christiansen (\%); n é o número de coletores; $\mathrm{S}_{\mathrm{i}}$ é a distância do ponto central do pivô ao i-ésimo ponto, ou número do coletor; $\mathrm{X}_{\mathrm{i}}$ é a lâmina de água coletada no i-ésimo coletor $(\mathrm{mm})$; X é o valor médio das lâminas de água coletada $(\mathrm{mm})$.

A p (Equação 12) é uma variável relacionada aos fatores edáficos, climáticos e da própria cultura. $\mathrm{O}$ valor de $\mathrm{p}$ deve ser maior ou igual a zero e menor ou igual a 1.

$$
\mathbf{p}=\frac{W+P e f}{E T m}
$$

em que, W é a água armazenada no solo (mm); Pefé o total da precipitação efetiva ocorrida durante o ciclo da cultura $(\mathrm{mm})$.

W e Pef foram obtidas por meio do balanço hídrico diário do software Irriplus, tomando $\mathrm{W}$ como a água disponível no solo (AD), descrita pela Equação 13, e a Pef pela Equação 14 .

$$
\boldsymbol{A D}=\frac{\text { Umidade }-P m}{10} d_{a} Z
$$

em que, AD é a água disponível no solo (mm); Umidade é a umidade real do solo (\% de peso); Pm é o ponto de murcha permanente (\% de solo); $\mathrm{d}_{\mathrm{a}}$ é a densidade do solo $\left(\mathrm{g} \mathrm{cm}^{-3}\right) ; \mathrm{Z}$ é a profundidade efetiva do sistema radicular $(\mathrm{cm})$.

$$
\text { Pef }=\sum\left[0,9177+1,8111 \log \left(P_{i}\right)-0,0097 \log \left(P_{i}\right)\left(\frac{s_{i-1}}{S_{i}} 100\right)\right]
$$

em que, Pef é o total de precipitação efetiva do ciclo (mm); $\mathrm{P}_{\mathrm{i}}$ é a precipitação do dia i (mm); $\mathrm{S}_{\mathrm{i}-1}$ é a água disponível no solo da primeira camada no dia $\mathrm{i}-1(\mathrm{~mm}) ; \mathrm{S}_{\mathrm{i}}$ é a capacidade de água total na primeira camada no dia $\mathrm{i}(\mathrm{mm})$.

Para avaliar os modelos, foi utilizada análise descritiva e testes de análise comparativa entre os dados estimados e observados. Os testes estatísticos utilizados 
AVALIAÇÃO DE MODELOS DE ESTIMATIVA DE PRODUTIVIDADE DA CANADE-AÇÚCAR IRRIGADA EM JAÍBA-MG

foram: teste-t pareado, erro relativo (MAE).

percentual (ERP), e erro absoluto médio

\section{RESULTADOS E DISCUSSÃO}

$\mathrm{Na}$ Tabela 3 encontram-se os resultados da safra de 2007/2008 estimados pelo MZA e pelo Modelo de Stewart. Em todas as parcelas a ym e $\mathrm{cN}$ foi igual a 65 $\mathrm{kg} \mathrm{ha}^{-1} \mathrm{~h}^{-1}$ e 0,5 , respectivamente, a menor Tm foi igual a $24,13{ }^{\circ} \mathrm{C}$, nas parcelas $3 \mathrm{e}$ 12 , e a maior igual a $25,46{ }^{\circ} \mathrm{C}$, na parcela 21, (Tabela 3).

Tabela 3 - Dados climatológicos de Jaíba, Minas Gerais, e produtividade da safra de 2007/2008 estimada pelo MZA e Modelo de Stewart.

\begin{tabular}{|c|c|c|c|c|c|c|c|c|c|c|c|c|}
\hline Parcela & $\bar{G}$ & $\mathrm{~F}$ & Rse & $\mathrm{Tm}$ & Yc & yon & $\mathrm{P}_{\max }$ & ETc & ETm & $\mathrm{P}$ & $\mathrm{P}_{\mathrm{obs}}$ & ERP \\
\hline 01 & 335 & 0,4697 & 351,62 & 24,56 & 418,46 & 222,61 & 172,09 & 1199,92 & 1628,43 & 117,75 & 102,42 & 14,97 \\
\hline 02 & 459 & 0,4750 & 354,01 & 24,37 & 420,59 & 223,93 & 235,71 & 1648,50 & 2613,50 & 131,27 & 117,21 & 12,00 \\
\hline 03 & 510 & 0,4797 & 356,18 & 24,13 & 422,49 & 225,10 & 261,93 & 1535,97 & 2471,10 & 142,99 & 128,19 & 11,55 \\
\hline 04 & 300 & 0,4700 & 351,75 & 24,28 & 418,80 & 222,83 & 154,25 & 1033,65 & 1416,62 & 104,21 & 105,39 & $-1,12$ \\
\hline 05 & 443 & 0,4734 & 353,29 & 24,44 & 419,89 & 223,53 & 227,45 & 1661,34 & 2535,48 & 133,35 & 148,49 & $-10,20$ \\
\hline 06 & 298 & 0,4697 & 351,64 & 24,28 & 418,72 & 222,78 & 153,23 & 1114,52 & 1403,92 & 115,33 & 122,16 & $-5,59$ \\
\hline 07 & 534 & 0,4813 & 356,92 & 24,15 & 423,04 & 225,42 & 274,20 & 1632,00 & 2575,83 & 153,63 & 148,79 & 3,25 \\
\hline 08 & 435 & 0,4725 & 352,91 & 24,46 & 419,53 & 223,32 & 223,33 & 1499,50 & 2421,79 & 121,27 & 138,36 & $-12,35$ \\
\hline 09 & 445 & 0,4736 & 353,38 & 24,43 & 419,98 & 223,59 & 228,48 & 1521,50 & 2187,19 & 145,04 & 135,40 & 7,12 \\
\hline 10 & 426 & 0,4715 & 352,44 & 24,48 & 419,09 & 223,07 & 218,69 & 1418,55 & 2446,01 & 108,46 & 122,21 & $-11,25$ \\
\hline 11 & 301 & 0,4701 & 351,81 & 24,29 & 418,84 & 222,85 & 154,76 & 1066,10 & 1421,46 & 108,33 & 112,03 & $-3,30$ \\
\hline 12 & 527 & 0,4809 & 356,76 & 24,13 & 422,93 & 225,36 & 270,63 & 1589,06 & 3099,87 & 112,35 & 122,76 & $-8,48$ \\
\hline 13 & 337 & 0,4696 & 351,58 & 24,59 & 418,42 & 222,59 & 173,10 & 1173,17 & 1638,05 & 114,15 & 124,04 & $-7,97$ \\
\hline 14 & 460 & 0,4750 & 354,02 & 24,37 & 420,60 & 223,93 & 236,22 & 1454,64 & 2258,13 & 135,36 & 141,58 & $-4,39$ \\
\hline 15 & 459 & 0,4749 & 353,98 & 24,37 & 420,55 & 223,91 & 235,70 & 1852,09 & 2347,19 & 176,04 & 161,92 & 8,72 \\
\hline 16 & 569 & 0,4812 & 356,91 & 24,29 & 422,89 & 225,32 & 292,04 & 1497,20 & 3371,60 & 97,21 & 84,51 & 15,03 \\
\hline 17 & 386 & 0,4660 & 349,97 & 24,52 & 417,03 & 221,80 & 198,18 & 992,96 & 2289,14 & 63,52 & 53,21 & 19,38 \\
\hline 18 & 444 & 0,4735 & 353,34 & 24,44 & 419,94 & 223,56 & 227,97 & 1503,01 & 2226,52 & 139,07 & 129,50 & 7,39 \\
\hline 19 & 396 & 0,4674 & 350,60 & 24,53 & 417,53 & 222,10 & 203,29 & 968,83 & 2281,31 & 62,94 & 65,39 & $-3,75$ \\
\hline 20 & 379 & 0,4652 & 349,60 & 24,49 & 416,89 & 221,68 & 194,66 & 1043,86 & 1980,15 & 84,21 & 92,29 & $-8,76$ \\
\hline 21 & 258 & 0,4375 & 337,70 & 25,46 & 406,38 & 215,39 & 132,48 & 906,05 & 1600,39 & 63,51 & 80,85 & $-21,45$ \\
\hline 22 & 439 & 0,4657 & 349,83 & 24,25 & 417,34 & 221,97 & 148,14 & 1052,64 & 1273,39 & 117,33 & 98,50 & 19,12 \\
\hline 23 & 302 & 0,4702 & 351,87 & 24,30 & 418,88 & 222,88 & 155,27 & 1080,22 & 1485,12 & 104,47 & 111,37 & $-6,20$ \\
\hline 24 & 369 & 0,4634 & 348,82 & 24,50 & 416,11 & 221,24 & 189,48 & 1124,85 & 2199,66 & 78,38 & 84,28 & $-7,00$ \\
\hline 25 & 427 & 0,4716 & 352,50 & 24,48 & 419,14 & 223,10 & 219,20 & 1513,70 & 2598,09 & 109,41 & 106,01 & 3,21 \\
\hline
\end{tabular}

G (dias) - duração do ciclo da cultura; $\mathrm{F}$ - fração do dia em que o sol fica encoberto por nuvens; Rse $\left(\mathrm{cal} \mathrm{cm}^{-1}\right.$ $\left.\mathrm{d}^{-1}\right)$ - radiação efetiva de ondas curtas para dias claros; Tm $\left({ }^{\circ} \mathrm{C}\right)$ - temperatura média; yc $\left(\mathrm{kg} \mathrm{ha}^{-1} \mathrm{~d}^{-1}\right)$ - taxa de produção bruta de matéria seca da cultura-padrão em dia sem nuvens; yon $\left(\mathrm{kg} \mathrm{ha}^{-1} \mathrm{~d}^{-1}\right)$ - taxa de produção bruta de matéria seca da cultura-padrão em dia completamente nublado; $\mathrm{P}_{\max }\left(\mathrm{t} \mathrm{ha}^{-1}\right)$ - produtividade máxima da cultura; ETc $(\mathrm{mm})$ - evapotranspiração da cultura; ETm $(\mathrm{mm})$ - evapotranspiração máxima da cultura; $\mathrm{P}(\mathrm{t}$ $\left.\mathrm{ha}^{-1}\right)$ - produtividade estimada; $\mathrm{P}_{\mathrm{obs}}\left(\mathrm{t} \mathrm{ha}^{-1}\right)$ - produtividade observada; ERP $(\%)$ - erro relativo percentual a produtividade observada e estimada. 


\section{AVALIAÇÃO DE MODELOS DE ESTIMATIVA DE PRODUTIVIDADE DA CANA- DE-AÇÚCAR IRRIGADA EM JAÍBA-MG}

A produtividade média estimada foi de $113,58 \mathrm{t} \mathrm{ha}^{-1}$ e a produtividade média observada em campo foi de $113,47 \mathrm{tha}^{-1}$, o MAE foi de 0,10 e o teste-t pareado não demonstrou diferença significativa, com 5\% de significância. Observa-se na Tabela 3, que o maior e menor ERP foi de $21,45 \%$ na parcela 21 e de $-1,12 \%$ na parcela 4 , respectivamente.

$\mathrm{Na}$ Figura 1 ajustou-se uma regressão da produtividade estimada em

A

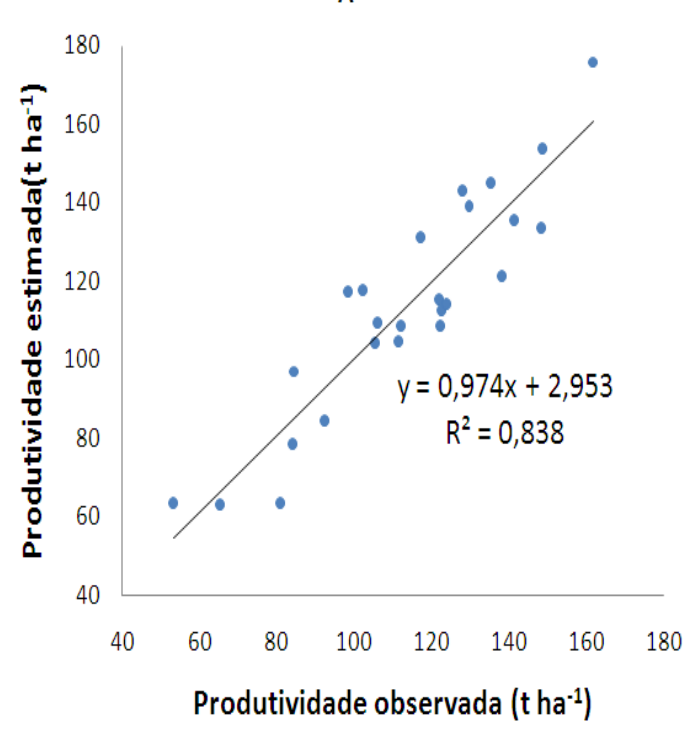

Figura 1 - Relação entre a produtividade estimada e observda em campo (a) e ERP da estimativa (b) da safra de 2007/2008 estimado pelo Modelo de Stewart.

$\mathrm{Na}$ Tabela 4 encontram-se os resultados da safra de 2008/2009 estimados pelo MZA e pelo Modelo de Stewart. Em todas as parcelas, a ym e cN foi igual a 65 $\mathrm{kg} \mathrm{ha} \mathrm{h}^{-1} \mathrm{~h}^{-1}$ e 0,5 , respectivamente, a menor função da produtividade observada em campo (a) e foi apresentado o ERP da estimativa de cada parcela (b), e verificouse que o Modelo de Stewart apresentou bom ajuste aos dados observados não evidenciando tendência de superestimativa ou subestimativa, com boa precisão, apresentado o coeficiente de determinação $\left(R^{2}\right)$ igual a 0,838 .

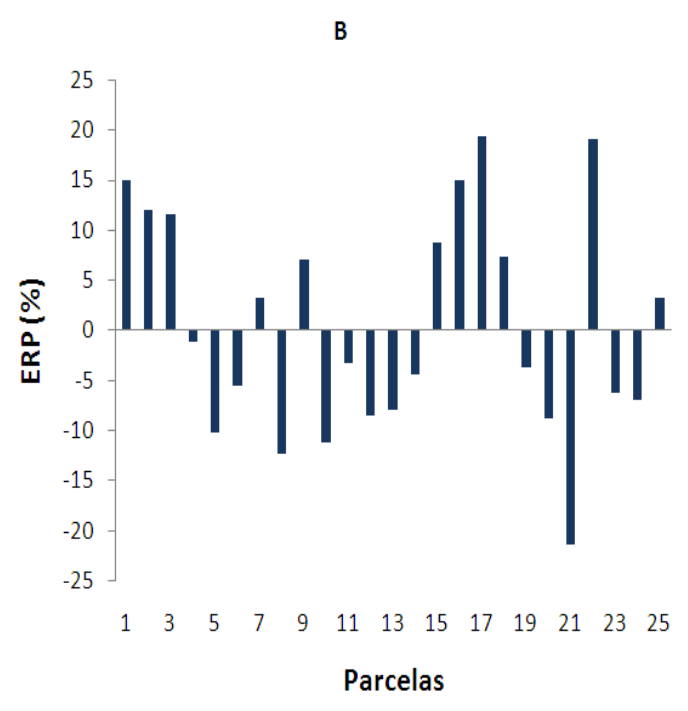

Tm foi igual a $24,30{ }^{\circ} \mathrm{C}$, na parcelas 19 , e a maior igual a $25,41{ }^{\circ} \mathrm{C}$, na parcela 18 , (Tabela 4). 
AVALIAÇÃO DE MODELOS DE ESTIMATIVA DE PRODUTIVIDADE DA CANADE-AÇÚCAR IRRIGADA EM JAÍBA-MG

Tabela 4 - Dados climatológicos de Jaíba, Minas Gerais, e produtividade da safra de 2008/2009 estimada pelo MZA e Modelo de Stewart.

\begin{tabular}{|c|c|c|c|c|c|c|c|c|c|c|c|c|}
\hline Parcela & G & $\mathrm{F}$ & Rse & $\mathrm{Tm}$ & $\mathrm{yc}$ & yon & $\mathrm{P}_{\max }$ & ETc & ETm & $\mathrm{P}$ & $\mathrm{P}_{\mathrm{obs}}$ & ERP \\
\hline 01 & 332 & 0,4589 & 346,81 & 24,76 & 414,64 & 220,37 & 170,62 & 1141,42 & 1363,38 & 128,42 & 127,02 & 1,10 \\
\hline 02 & 395 & 0,4666 & 350,24 & 24,72 & 417,19 & 221,90 & 202,76 & 1398,71 & 1795,61 & 148,98 & 139,39 & 6,88 \\
\hline 03 & 388 & 0,4669 & 350,36 & 24,66 & 417,38 & 222,01 & 199,22 & 1358,26 & 1791,85 & 141,37 & 156,48 & $-9,66$ \\
\hline 04 & 400 & 0,4685 & 351,10 & 24,64 & 417,97 & 222,37 & 205,36 & 1404,4 & 1787,92 & 152,5 & 140,04 & 8,90 \\
\hline 05 & 356 & 0,4619 & 348,14 & 24,62 & 415,51 & 220,89 & 182,81 & 1300,46 & 1622,17 & 139,3 & 122,85 & 13,39 \\
\hline 06 & 381 & 0,4642 & 349,17 & 24,74 & 416,31 & 221,36 & 195,59 & 1336,84 & 2055,04 & 113,56 & 119,28 & $-4,80$ \\
\hline 07 & 381 & 0,4658 & 349,88 & 24,54 & 417,11 & 221,85 & 195,69 & 1376,17 & 1698,8 & 151,09 & 161,76 & $-6,60$ \\
\hline 08 & 322 & 0,4650 & 349,50 & 24,44 & 416,98 & 221,76 & 158,36 & 935,91 & 1203,91 & 116,06 & 121,24 & $-4,27$ \\
\hline 09 & 404 & 0,4686 & 351,13 & 24,65 & 417,97 & 222,37 & 207,39 & 1325,38 & 1814,06 & 140,35 & 134,94 & 4,01 \\
\hline 10 & 380 & 0,4657 & 349,85 & 24,63 & 416,97 & 221,76 & 195,13 & 1382,93 & 1741,07 & 146,96 & 155,04 & $-5,21$ \\
\hline 11 & 290 & 0,4621 & 348,24 & 24,32 & 416,05 & 221,22 & 149,18 & 921,98 & 1090,91 & 121,46 & 120,28 & 0,98 \\
\hline 12 & 340 & 0,4591 & 346,93 & 24,71 & 414,36 & 220,22 & 174,55 & 1192,36 & 1542,38 & 127,02 & 136,42 & $-6,89$ \\
\hline 13 & 293 & 0,4486 & 342,38 & 25,19 & 410,26 & 217,72 & 150,37 & 1028,16 & 1289,29 & 113,82 & 117,57 & $-3,19$ \\
\hline 14 & 347 & 0,4604 & 347,47 & 24,67 & 414,87 & 220,52 & 178,16 & 1255,89 & 1580,38 & 134,27 & 123,56 & 8,67 \\
\hline 15 & 398 & 0,4683 & 350,98 & 24,65 & 417,87 & 222,32 & 204,33 & 1609,98 & 1843,27 & 173,3 & 168,5 & 2,85 \\
\hline 16 & 304 & 0,4687 & 351,20 & 24,45 & 418,38 & 222,59 & 151,70 & 785,07 & 1138,19 & 95,22 & 105,81 & $-10,01$ \\
\hline 17 & 276 & 0,4437 & 340,27 & 25,31 & 408,49 & 216,66 & 141,67 & 785,29 & 1182,55 & 84,56 & 99,63 & $-15,13$ \\
\hline 18 & 237 & 0,4311 & 335,06 & 25,41 & 404,30 & 214,16 & 121,78 & 729,95 & 933,83 & 89,88 & 102,93 & $-12,68$ \\
\hline 19 & 282 & 0,4603 & 347,43 & 24,30 & 415,41 & 220,83 & 145,09 & 861,38 & 1041,13 & 115,03 & 114,34 & 0,60 \\
\hline 20 & 361 & 0,4627 & 348,50 & 24,60 & 415,85 & 221,08 & 185,39 & 1215,82 & 1661,96 & 125,67 & 116,47 & 7,90 \\
\hline 21 & 289 & 0,4619 & 348,14 & 24,32 & 415,98 & 221,17 & 148,67 & 890,39 & 1085,07 & 116,66 & 116,85 & $-0,16$ \\
\hline 22 & 288 & 0,4821 & 357,28 & 24,49 & 423,30 & 225,58 & 136,83 & 640,78 & 988,38 & 79,09 & 94,95 & $-16,70$ \\
\hline 23 & 291 & 0,4651 & 349,56 & 24,33 & 417,11 & 221,84 & 149,68 & 849,57 & 1101,56 & 108,59 & 97,69 & 11,16 \\
\hline 24 & 288 & 0,4821 & 357,28 & 24,49 & 423,30 & 225,58 & 136,83 & 757,71 & 988,38 & 98,51 & 89,06 & 10,61 \\
\hline 25 & 315 & 0,4693 & 351,47 & 24,45 & 418,61 & 222,72 & 150,68 & 807,8 & 1127,81 & 99,37 & 96,73 & 2,73 \\
\hline 26 & 292 & 0,4626 & 348,44 & 24,33 & 416,21 & 221,31 & 150,21 & 899,81 & 1103,67 & 116,91 & 116,24 & 0,58 \\
\hline 27 & 292 & 0,4754 & 354,21 & 24,49 & 420,83 & 224,06 & 143,50 & 786,98 & 1057,28 & 99,48 & 93,84 & 6,01 \\
\hline
\end{tabular}

G (dias) - duração do ciclo da cultura; $\mathrm{F}$ - fração do dia em que o sol fica encoberto por nuvens; Rse (cal cm ${ }^{-1}$ $\left.\mathrm{d}^{-1}\right)$ - radiação efetiva de ondas curtas para dias claros; $\mathrm{Tm}\left({ }^{\circ} \mathrm{C}\right)$ - temperatura média; $\mathrm{yc}\left(\mathrm{kg} \mathrm{ha}^{-1} \mathrm{~d}^{-1}\right)$ - taxa de produção bruta de matéria seca da cultura-padrão em dia sem nuvens; yon $\left(\mathrm{kg} \mathrm{ha}^{-1} \mathrm{~d}^{-1}\right)$ - taxa de produção bruta de matéria seca da cultura-padrão em dia completamente nublado; $\mathrm{P}_{\max }\left(\mathrm{t} \mathrm{ha}{ }^{-1}\right)$ - produtividade máxima da cultura; ETc $(\mathrm{mm})$ - evapotranspiração da cultura; ETm $(\mathrm{mm})$ - evapotranspiração máxima da cultura; P $(\mathrm{t}$ $\left.\mathrm{ha}^{-1}\right)$ - produtividade estimada; $\mathrm{P}_{\mathrm{obs}}\left(\mathrm{t} \mathrm{ha}^{-1}\right)$ - produtividade observada; ERP $(\%)$ - erro relativo percentual a produtividade observada e estimada.

A produtividade média estimada foi de $121,39 \mathrm{t} \mathrm{ha}^{-1}$ e a produtividade média observada em campo foi de 121,81 $\mathrm{t} \mathrm{ha}^{-1}$. De acordo com Tabela 4, o maior ERP foi de $-16,7 \%$ na Parcela 22 e o menor ERP de $-0,16 \%$ na Parcela 21. O MAE foi de 0,07 e o teste-t pareado não demonstrou diferença significativa, com $5 \%$ de significância. Observa-se na Figura 2, que o modelo não evidenciou tendência de superestimativa ou subestimativa, como aconteceu na estimativa da safra de 2007/2008, apresentando bom ajuste aos dados observados, com boa precisão $\left(\mathrm{R}^{2}=\right.$ 0,832 ).
$\mathrm{Na}$ Tabela 5 encontram-se apresentado os resultados da safra de 2007/2008 estimados pelo Modelo de Mantovani. Foram utilizados os mesmos dados de $\mathrm{P}_{\max }$ estimado no Modelo de Stewart nas safras de 2007/2008 (Tabela 3) e 2008/2009 (Tabela 4), levando em consideração que foram simulados os

mesmos dados. Segundo a SADA AgroEnergia, o CUC médio dos pivôs centrais é de $90 \%$ de uniformidade, deste modo, considerou-se esta uniformidade em todas as parcelas das safras de 2007/2008 e $2008 / 2009$. 
A

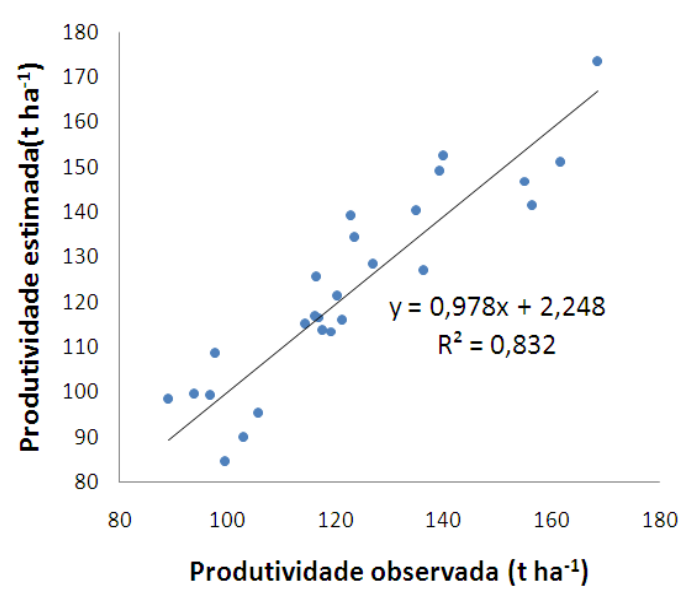

B

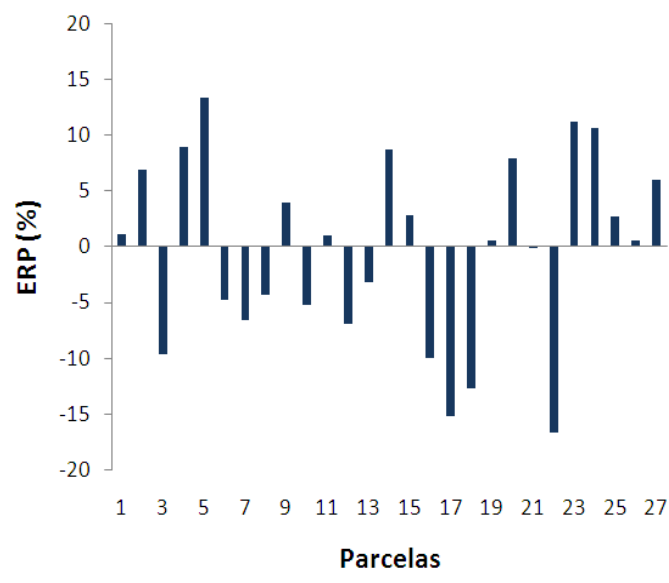

Figura 2 - Relação entre a produtividade estimada e observda em campo (a) e ERP da estimativa (b) da safra de 2008/2009 estimado pelo Modelo de Stewart.

Tabela 5 - Dados de irrigação, solo e produtividade da safra de 2007/2008 estimada pelo Modelo de Mantovani.

\begin{tabular}{ccccccccccc}
\hline Parcela & $\mathrm{P}_{\max }$ & $\mathrm{Lr}$ & $\mathrm{Lb}$ & $\mathrm{Cd}$ & $\mathrm{AD}$ & $P e f$ & $\mathrm{p}$ & $\mathrm{P}$ & $\mathrm{P}_{\text {obs }}$ & ERP \\
\hline 01 & 172,09 & 1199,92 & 1667,63 & 0,062 & 30,20 & 235,51 & 0,163 & 161,46 & 102,42 & 57,64 \\
02 & 235,71 & 1648,50 & 1992,47 & 0,039 & 42,00 & 352,46 & 0,151 & 226,25 & 117,21 & 93,03 \\
03 & 261,93 & 1535,97 & 1823,84 & 0,037 & 41,67 & 284,02 & 0,132 & 251,85 & 128,19 & 96,47 \\
04 & 154,25 & 1033,65 & 1454,09 & 0,063 & 30,20 & 199,56 & 0,162 & 144,43 & 105,39 & 37,04 \\
05 & 227,45 & 1661,34 & 1937,65 & 0,035 & 39,84 & 385,55 & 0,168 & 219,54 & 148,49 & 47,85 \\
06 & 153,23 & 1114,52 & 1542,88 & 0,061 & 43,95 & 202,24 & 0,175 & 143,98 & 122,16 & 17,86 \\
07 & 274,20 & 1632,00 & 1957,46 & 0,038 & 52,80 & 244,44 & 0,115 & 263,05 & 148,79 & 76,79 \\
08 & 223,33 & 1499,50 & 1786,52 & 0,037 & 52,80 & 322,18 & 0,155 & 214,86 & 138,36 & 55,29 \\
09 & 228,48 & 1521,50 & 1937,99 & 0,048 & 54,73 & 126,78 & 0,083 & 216,52 & 135,40 & 59,91 \\
10 & 218,69 & 1418,55 & 1624,21 & 0,033 & 52,80 & 401,76 & 0,186 & 211,62 & 122,21 & 73,16 \\
11 & 154,76 & 1066,10 & 1359,03 & 0,048 & 43,95 & 188,67 & 0,164 & 147,35 & 112,03 & 31,53 \\
12 & 270,63 & 1589,06 & 1786,66 & 0,032 & 50,40 & 342,03 & 0,127 & 261,57 & 122,76 & 113,07 \\
13 & 173,10 & 1173,17 & 1636,13 & 0,062 & 30,20 & 215,38 & 0,150 & 162,14 & 124,04 & 30,71 \\
14 & 236,22 & 1454,64 & 1763,57 & 0,040 & 55,03 & 265,48 & 0,142 & 226,53 & 141,58 & 60,00 \\
15 & 235,70 & 1852,09 & 2223,81 & 0,038 & 65,25 & 186,77 & 0,107 & 226,00 & 161,92 & 39,58 \\
16 & 292,04 & 1497,20 & 1623,37 & 0,032 & 50,40 & 349,01 & 0,118 & 282,18 & 84,51 & 233,90 \\
17 & 198,18 & 992,96 & 1066,01 & 0,033 & 42,00 & 423,50 & 0,203 & 192,00 & 53,21 & 260,84 \\
18 & 227,97 & 1503,01 & 1815,55 & 0,039 & 57,75 & 239,11 & 0,133 & 218,65 & 129,50 & 68,84 \\
19 & 203,29 & 968,83 & 992,23 & 0,041 & 49,10 & 377,48 & 0,187 & 195,11 & 65,39 & 198,38 \\
20 & 194,66 & 1043,86 & 1250,06 & 0,038 & 40,69 & 354,76 & 0,200 & 187,55 & 92,29 & 103,22 \\
21 & 132,48 & 906,05 & 1058,69 & 0,035 & 40,80 & 343,79 & 0,240 & 128,25 & 80,85 & 58,63 \\
22 & 148,14 & 1052,64 & 1363,92 & 0,050 & 54,38 & 160,33 & 0,169 & 140,7 & 98,50 & 42,84 \\
23 & 155,27 & 1080,22 & 1486,97 & 0,060 & 30,20 & 225,62 & 0,172 & 146,00 & 111,37 & 31,09 \\
24 & 189,48 & 1124,85 & 1283,45 & 0,033 & 55,80 & 386,47 & 0,201 & 183,52 & 84,28 & 117,75 \\
25 & 219,20 & 1513,70 & 1822,12 & 0,039 & 42,00 & 342,05 & 0,148 & 210,51 & 106,01 & 98,58
\end{tabular}

$\mathrm{P}_{\max }\left(\mathrm{t} \mathrm{ha}^{-1}\right)$ - produtividade máxima da cultura; $\mathrm{Lr}(\mathrm{mm})$ - lâmina requerida; $\mathrm{Lb}(\mathrm{mm})$ - lâmina de irrigação aplicada e precipitação; Cd (adimensional) - coeficiente de déficit; AD (mm) - água disponível no solo; Pef (mm) - precipitação efetiva; $\mathrm{p}$ (adimensional) - fração da evapotranspiração máxima da cultura suprida por outras fontes de água diferentes da irrigação; $\mathrm{P}\left(\mathrm{t} \mathrm{ha}^{-1}\right)$ - produtividade estimada; $\mathrm{P}_{\mathrm{obs}}\left(\mathrm{t} \mathrm{ha}^{-1}\right)$ - produtividade observada; ERP (\%) - erro relativo percentual a produtividade observada e estimada. 


\section{AVALIAÇÃO DE MODELOS DE ESTIMATIVA DE PRODUTIVIDADE DA CANA- DE-AÇÚCAR IRRIGADA EM JAÍBA-MG}

De acordo com a Tabela 5, o maior e menor ERP foi de $260,84 \%$ na parcela $17 \mathrm{e}$ $17,86 \%$ na parcela 6 , respectivamente. A produtividade média estimada foi de 198,46 $\mathrm{t} \mathrm{ha}^{-1}$ e a produtividade média observada em campo foi de 113,47 $\mathrm{t} \mathrm{ha}^{-1}$. $O$ teste-t pareado demonstrou diferença significativa, com $5 \%$ de significância, e o MAE foi de 0,84 .

A

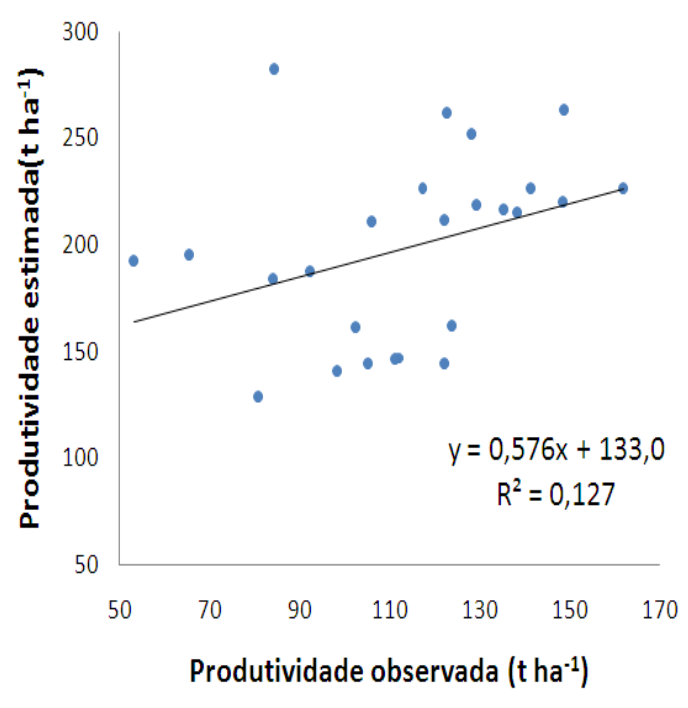

$\mathrm{Na}$ Figura 3, ajustou-se uma regressão da produtividade estimada em função da produtividade observada em campo (a) e foi apresentado o ERP de cada parcela (b), e verificou-se que o Modelo de Mantovani superestimou todas as produtividades observadas em campo.

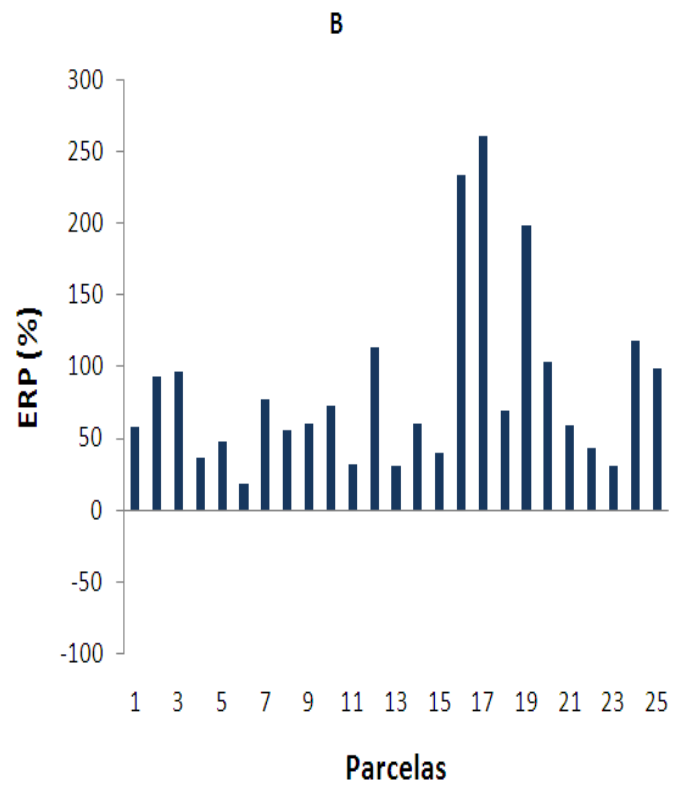

Figura 3 - Relação entre a produtividade estimada e observda em campo (a) e ERP da estimativa (b) da safra de 2007/2008 estimado pelo Modelo de Mantovani.

Comparando-se a produtividade estimada com a $\mathrm{P}_{\max }$ de todas as parcelas (Tabela 5), nota-se que houve mínima diferença entre elas, conforme pode ser observado. Na Figura 4, ajustou-se uma regressão da produtividade estimada em função da $\mathrm{P}_{\max }$, e comprovou-se que o modelo seguiu a mesma tendência em todas as parcelas, apresentando $\mathrm{R}^{2}$ igual a 0,998 .

No Modelo de Mantovani a produção máxima é alcançada se o $\mathrm{Cd}$ for igual a zero, pois este quantifica o déficit de água a que está submetida uma área da superfície irrigada. De acordo com as estimativas de Cd (Tabela 5), todas foram relativamente baixos sendo a maior igual a 0,063 na parcela 4 .

$\mathrm{O}$ Cd é estimado em função da $\mathrm{L}_{\mathrm{b}}, \mathrm{L}_{\mathrm{r}}$ e CUC, deste modo, como todas as estimativas de produtividade foram similares, comparando-se com a $\mathrm{P}_{\max }$ (Figura 4), foram selecionadas as três primeiras parcelas, 1, 2 e 3, e foi simulado o $\mathrm{Cd}$ novamente variando o CUC mantendo os mesmos valores de $\mathrm{L}_{\mathrm{b}}$ e $\mathrm{L}_{\mathrm{r}}$. A simulação foi realizada variando o CUC com $60 \%, 70 \%, 80 \%$ e $90 \%$ de uniformidade. 


\section{AVALIAÇÃO DE MODELOS DE ESTIMATIVA DE PRODUTIVIDADE DA CANA- DE-AÇÚCAR IRRIGADA EM JAÍBA-MG}

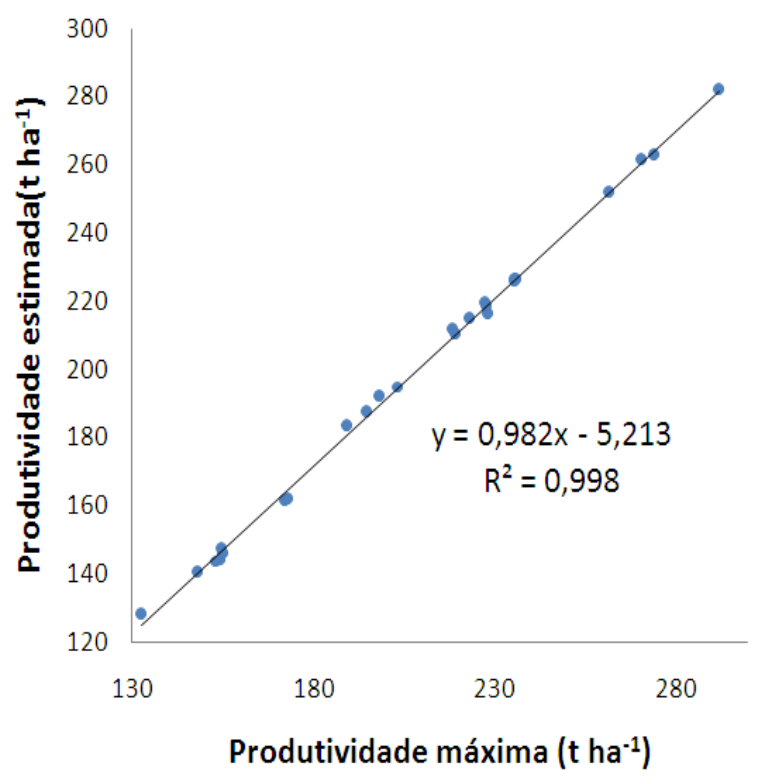

Figura 4 - Relação entre a produtividade estimada pelo Modelo de Mantovani e produtividade máxima da safra de 2007/2008.

Na Figura 5 encontra-se ilustrado o demonstrativo da produtividade estimada variando o CUC nas três parcelas, onde nota-se que o CUC apesar de ser um fator determinante no $\mathrm{Cd}$, este não influenciou diretamente nas superestimativas observada na Figura 3. Nas três parcelas simuladas com CUC igual a 60\%, a produtividade estimada foi de 143,08, 195,39 e $215,78 \mathrm{t} \mathrm{ha}^{-1}$, respectivamente, enquanto a produtividade observada em campo destas mesmas parcelas foi de $102,42,117,21$ e 128,21 t $\mathrm{ha}^{-1}$, respectivamente.

Nesta pesquisa, o Cd foi estimado com o acumulativo de todas as lâminas de irrigação aplicada, entretanto, ele deveria ser estimado para cada lâmina aplicada durante o ciclo com o determinado CUC, pois de acordo com Heinemann et al. (1998), a uniformidade de aplicação é fortemente influenciada por fatores climáticos e não climáticos, que são os relacionados ao próprio equipamento de irrigação, como a pressão de operação do emissor, velocidade e alinhamento das torres e altura do emissor. Segundo Mantovani et al. (2010), a maioria dos modelos que inclui uniformidade de distribuição de água normalmente apresenta um requerimento de dados de entrada que dificultam a sua utilização em nível de campo. 
AVALIAÇÃO DE MODELOS DE ESTIMATIVA DE PRODUTIVIDADE DA CANADE-AÇÚCAR IRRIGADA EM JAÍBA-MG

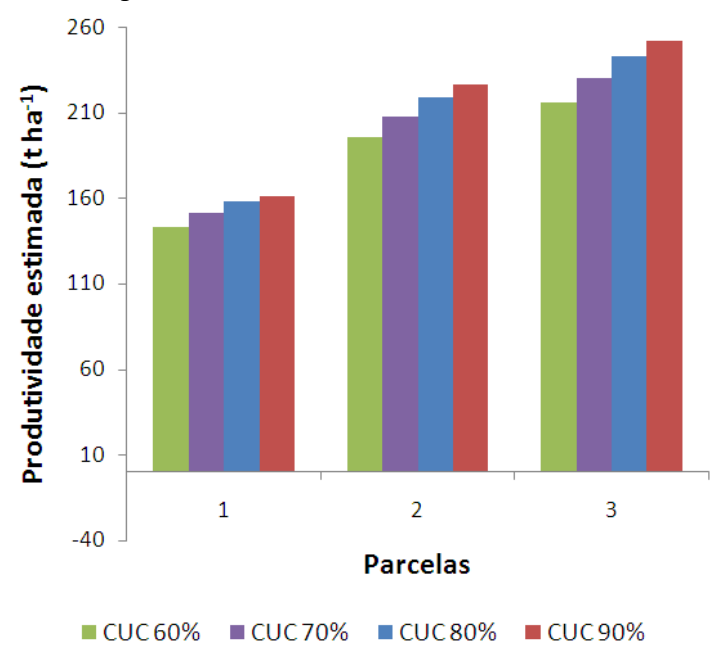

Figura 5 - Produtividade estimada pelo Modelo de Mantovani variando o CUC em 60, 70, 80 e $90 \%$.

$\mathrm{Na}$ Tabela 6 encontram-se 2008/2009 estimados pelo Modelo de apresentado os resultados da safra de Mantovani.

Tabela 6 - Dados de irrigação, solo e produtividade da safra de 2008/2009 estimada pelo Modelo de Mantovani.

\begin{tabular}{|c|c|c|c|c|c|c|c|c|c|c|}
\hline Parcela & $\mathrm{P}_{\max }$ & $\mathrm{Lr}$ & $\mathrm{Lb}$ & $\mathrm{Cd}$ & $\mathrm{AD}$ & $P e f$ & $\mathrm{p}$ & $\mathrm{P}$ & $\mathrm{P}_{\mathrm{obs}}$ & ERP \\
\hline 01 & 170,62 & 1141,42 & 1753,66 & 0,112 & 43,49 & 236,95 & 0,2057 & 152,37 & 127,02 & 19,96 \\
\hline 02 & 202,76 & 1398,71 & 1954,83 & 0,062 & 36,68 & 188,54 & 0,1254 & 189,48 & 139,39 & 35,94 \\
\hline 03 & 199,22 & 1358,26 & 1886,57 & 0,062 & 50,43 & 230,23 & 0,1566 & 186,82 & 156,48 & 19,39 \\
\hline 04 & 205,36 & 1404,4 & 2007,95 & 0,066 & 36,69 & 258,68 & 0,1652 & 191,84 & 140,04 & 36,99 \\
\hline 05 & 182,81 & 1300,46 & 1943,67 & 0,072 & 48,54 & 165,25 & 0,1318 & 169,19 & 122,85 & 37,72 \\
\hline 06 & 195,59 & 1336,84 & 1848,96 & 0,061 & 30,20 & 276,47 & 0,1492 & 183,45 & 119,28 & 53,80 \\
\hline 07 & 195,69 & 1376,17 & 2077,93 & 0,073 & 39,42 & 240,75 & 0,1649 & 181,43 & 161,76 & 12,16 \\
\hline 08 & 158,36 & 935,91 & 1496,14 & 0,079 & 29,83 & 189,36 & 0,1821 & 146,08 & 121,24 & 20,49 \\
\hline 09 & 207,39 & 1325,38 & 1813,99 & 0,059 & 36,69 & 236,54 & 0,1506 & 194,88 & 134,94 & 44,42 \\
\hline 10 & 195,13 & 1382,93 & 1976,96 & 0,066 & 54,43 & 185,69 & 0,1379 & 181,89 & 155,04 & 17,32 \\
\hline 11 & 149,18 & 921,98 & 1520,44 & 0,082 & 43,42 & 163,21 & 0,1894 & 137,28 & 120,28 & 14,13 \\
\hline 12 & 174,55 & 1192,36 & 1746,72 & 0,069 & 41,50 & 242,06 & 0,1838 & 162,77 & 136,42 & 19,32 \\
\hline 13 & 150,37 & 1028,16 & 1489,68 & 0,068 & 41,42 & 201,37 & 0,1883 & 140,48 & 117,57 & 19,49 \\
\hline 14 & 178,16 & 1255,89 & 1712,14 & 0,059 & 55,15 & 313,19 & 0,2331 & 168,55 & 123,56 & 36,41 \\
\hline 15 & 204,33 & 1609,98 & 2218,68 & 0,060 & 54,46 & 152,69 & 0,1124 & 191,21 & 168,50 & 13,48 \\
\hline 16 & 151,70 & 785,07 & 1246,31 & 0,078 & 29,82 & 178,52 & 0,183 & 140,06 & 105,81 & 32,37 \\
\hline 17 & 141,67 & 785,29 & 1083,76 & 0,061 & 52,02 & 255,36 & 0,2599 & 134,06 & 99,63 & 34,56 \\
\hline 18 & 121,78 & 729,95 & 1105,50 & 0,073 & 51,90 & 185,58 & 0,2543 & 113,81 & 102,93 & 10,57 \\
\hline 19 & 145,09 & 861,38 & 1456,29 & 0,084 & 43,41 & 163,25 & 0,1985 & 133,31 & 114,34 & 16,59 \\
\hline 20 & 185,39 & 1215,82 & 1714,76 & 0,064 & 41,53 & 218,39 & 0,1564 & 173,44 & 116,47 & 48,91 \\
\hline 21 & 148,67 & 890,39 & 1486,68 & 0,083 & 29,81 & 126,84 & 0,1444 & 135,97 & 116,85 & 16,36 \\
\hline 22 & 136,83 & 640,78 & 993,36 & 0,076 & 34,38 & 156,36 & 0,193 & 126,79 & 94,95 & 33,53 \\
\hline 23 & 149,68 & 849,57 & 1413,28 & 0,083 & 29,81 & 151,36 & 0,1645 & 137,24 & 97,69 & 40,49 \\
\hline 24 & 136,83 & 757,71 & 1066,10 & 0,063 & 40,18 & 154,25 & 0,1967 & 128,47 & 89,06 & 44,25 \\
\hline 25 & 150,68 & 807,80 & 1280,99 & 0,078 & 40,24 & 129,31 & 0,1503 & 138,67 & 96,73 & 43,36 \\
\hline 26 & 150,21 & 899,81 & 1520,56 & 0,084 & 29,81 & 181,81 & 0,1917 & 137,93 & 116,24 & 18,66 \\
\hline 27 & 143,50 & 786,98 & 1311,56 & 0,083 & 40,21 & 129,44 & 0,1605 & 131,5 & 93,84 & 40,13 \\
\hline
\end{tabular}

$\mathrm{P}_{\max }\left(\mathrm{t} \mathrm{ha}{ }^{-1}\right)$ - produtividade máxima da cultura; $\mathrm{Lr}(\mathrm{mm})$ - lâmina requerida; $\mathrm{Lb}(\mathrm{mm})$ - lâmina de irrigação aplicada e precipitação; Cd (adimensional) - coeficiente de déficit; AD (mm) - água disponível no solo; Pef $(\mathrm{mm})$ - precipitação efetiva; $\mathrm{p}$ (adimensional) - fração da evapotranspiração máxima da cultura suprida por outras fontes de água diferentes da irrigação; $\mathrm{P}\left(\mathrm{t} \mathrm{ha}^{-1}\right)$ - produtividade estimada; $\mathrm{P}_{\mathrm{obs}}\left(\mathrm{t}\right.$ ha $\left.{ }^{-1}\right)$ - produtividade observada; ERP $(\%)$ - erro relativo percentual a produtividade observada e estimada. 


\section{AVALIAÇÃO DE MODELOS DE ESTIMATIVA DE PRODUTIVIDADE DA CANA- DE-AÇÚCAR IRRIGADA EM JAÍBA-MG}

A produtividade média estimada foi de $155,89 \mathrm{t} \mathrm{ha}^{-1} \mathrm{e}$ a produtividade média observada em campo foi de $121,81 \mathrm{t} \mathrm{ha}^{-1}$. O maior e menor ERP foi de $53,80 \%$ na parcela 6 e $10,57 \%$ na parcela 18 ,

A

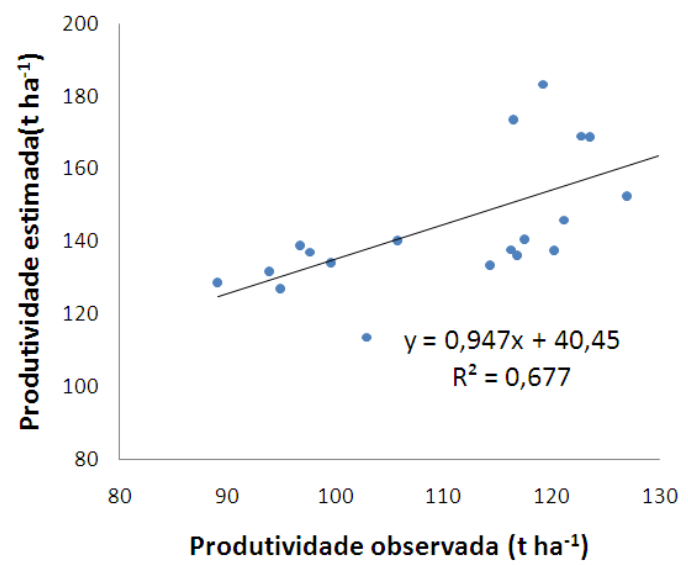

respectivamente, (Tabela 6). $\mathrm{O}$ teste-t pareado demonstrou diferença significativa, com 5\% de significância, e o MAE foi de 0,34.

Figura 6 - Relação entre a produtividade estimada e observda em campo (a) e ERP da estimativa (b) da safra de 2008/2009 estimado pelo Modelo de Mantovani.

Observa-se na Figura 6, que o modelo tendeu o mesmo erro de estimativa da safra de 2007/2008, superestimando todas as produtividades observadas em campo. Outro ponto similar é a diferença entre a produtividade observada e a $\mathrm{P}_{\max }$, com mínima diferença.
$\mathrm{Na}$ Figura 7, ajustou-se uma regressão da produtividade estimada em função da $\mathrm{P}_{\max }$, e comprovou-se que $\mathrm{o}$ modelo seguiu a mesma tendência em todas as parcelas, apresentando $\mathrm{R}^{2}$ igual a 0,994 .

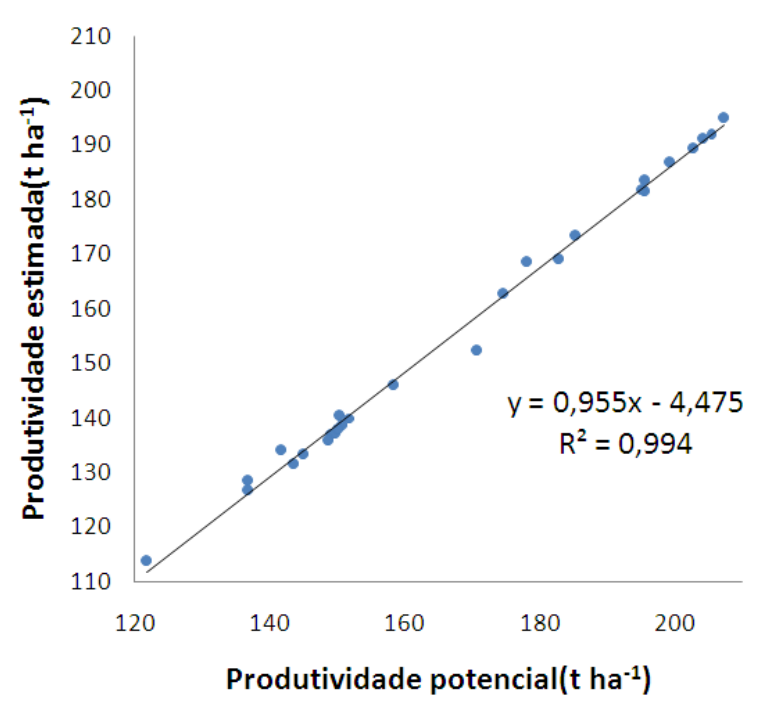

Figura 7 - Relação entre a produtividade estimada pelo Modelo de Mantovani e produtividade máxima da safra de 2008/2009. 


\section{AVALIAÇÃO DE MODELOS DE ESTIMATIVA DE PRODUTIVIDADE DA CANA- DE-AÇÚCAR IRRIGADA EM JAÍBA-MG}

\section{CONCLUSÕES}

O modelo mais apropriado para estimar a produtividade da cana-de-açúcar RB 86-7515, no município de Jaíba, estado de Minas Gerais, foi o Modelo de Stewart.

As estimativas do modelo de Stewart, nas duas safras, não apresentaram diferença significativa pelo teste-t pareado entre as médias de produtividade estimadas

\section{REFERÊNCIAS}

ALLEN, R.G.; PEREIRA, L.S.; RAES, D.; SMITH, M. Guidelines for computing crop water requeriments. FAO Irrigation and Drainage, 56. Rome: FAO, 1998. 308 p.

CHRISTIANSEN, J.E. Irrigation by Sprinkling. Berkeley: California Agricultural Station, 1942. 124 p.

DOORENBOS, J.; KASSAN, A.H. Yield response to water. FAO Irrigation and Drainage, 33. Rome: FAO, 1979. 193 p.

DOORENBOS, J.; PRUITT, J,O. Guidelines for predicting crop water requirements. Paper, 24. Rome: FAO, 1977. $179 \mathrm{p}$.

FACCIOLI, G.G. Modelagem da uniformidade e da lâmina de irrigação na produtividade do feijoeiro. 2002. 192 f. Tese (Doutorado em Engenharia Agrícola) - Universidade Federal de Viçosa, Viçosa.

HEERMANN, D.F.; HEIN, P.R. Performance characteristics of self propelled center-pivot sprinkler irrigation system. Transactions of the ASAE, v. 11, n. 1, p. 11-15, 1968.

Rev. Bras. Agric. Irrigada v. 7, no. 2, p. 112 - 127 e observadas em campo e apresentou baixo erro absoluto médio.

O modelo de Mantovani apresentou nas duas safras diferença significativa pelo teste-t pareado e superestimou a produtividade observada em campo. O coeficiente de déficit, calculado por ciclo total, influenciou na superestimativa da produtividade em todas as parcelas.

HEINEMANN, A.B.; FRIZZONE, J.A.; PINTO, J.M.; FEITOSA FILHO, J.C. Influencia da altura do emissor na uniformidade de distribuição da água de um sistema tipo pivô central. Pesquisa Agropecuária Brasileira, v. 33, n. 9, p. 1487-1491, 1998.

LÓPEZ-MATA, E.; TARJUELLO, J.M.; JUAN, J.A.; BALLESTEROS, R.; DOMÍNGUEZ, A. Effect of irrigation uniformity on the profitability of crops. Agricultural Water Management, v. 98, n. 1, p. 190-198, 2010.

MANTOVANI, E.C. Desarrollo y evaluacion de modelos para el manejo del riego: estimación de la evaporatranspiración e efectos de la uniformidad de la aplicación del riego sobre la produção de los cultivos. 1993. 357 f. Tese (Doutorado em Engenharia Agrícola) - Universidad de Cordoba, Cordoba, Espanha.

MANTOVANI, E.C.; BERNARDO, S.; PALARETTI, L.F. Irrigação: princípios e métodos. 3.ed. Viçosa: UFV, 2009. 357 p.

MANTOVANI, E. C.; FACCIOLI, G. G.; LEAL, B. G.; COSTA, L. C.; SOARES, A. A.; FREITAS, P. S. L. Determining the deficit coefficient as a function of 
AVALIAÇÃO DE MODELOS DE ESTIMATIVA DE PRODUTIVIDADE DA CANADE-AÇÚCAR IRRIGADA EM JAÍBA-MG

irrigation depth and distribution uniformity. Revista Brasileira de Engenharia Agrícola e Ambiental, v. 14, n. 3, p. 253-260, 2010.

MANTOVANI, E. C; MONTES, D. R. P; VIEIRA, G. H. S.; RAMOS, M. M.; SOARES, A. A. Estimativa de produtividade da cultura do feijão irrigado em Cristalina-GO, para diferentes lâminas de irrigação como função da uniformidade de aplicação. Engenharia Agrícola, v. 32, n. 1, p. 110-120, 2012.

MEGDA, M. X. V.; TRIVELIN, P. C. O.; FRANCO, H. C. J.; OTTO, R.; VITTI, A. C. Eficiência agronômica de adubos nitrogenados em soqueira de cana-deaçúcar colhida sem queima. Pesquisa Agropecuária Brasileira, v. 47, n. 12, p. 1681-1690, 2012.
PEREIRA, L.S.; VALERO, J.A. de J.; BUENDÍA, M.R.P.; MARTÍN-BENITO, J.M.T. El riego y sus tecnologías. Albacete: CREA-UCLM, 2010. 296 p.

SILVA, L. L.; COSTA, R. F.; CAMPOS, J. H. B.; DANTAS, R. T. Influência das precipitações na produtividade agrícola no Estado da Paraíba, Revista Brasileira de Engenharia Agrícola e Ambiental, v. 13, n. 4, p. 454-461, 2009. 